Open Access

\title{
Building a better neonatal mouse model to understand infant respiratory syncytial virus disease
}

Dahui You ${ }^{1,2}$, David T. Siefker ${ }^{1,2}$, Bishwas Shrestha ${ }^{1,2}$, Jordy Saravia ${ }^{1,2}$ and Stephania A. Cormier ${ }^{1,2^{*}}$

\begin{abstract}
Background: Respiratory syncytial virus (RSV) is the number one cause of lower respiratory tract infection in infants; and severe RSV infection in infants is associated with asthma development. Today, there are still no vaccines or specific antiviral therapies against RSV. The mechanisms of RSV pathogenesis in infants remain elusive. This is partly due to the fact that the largely-used mouse model is semi-permissive for RSV. The present study sought to determine if a better neonatal mouse model of RSV infection could be obtained using a chimeric virus in which the F protein of A2 strain was replaced with the F protein from the line 19 clinical isolate (rA2-19F).
\end{abstract}

Methods: Five-day-old pups were infected with the standard laboratory strain A2 or rA2-19F and various immunological and pathophysiological parameters were measured at different time points post infection, including lung histology, bronchoalveolar lavage fluid (BALF) cellularity and cytokines, pulmonary T cell profile, and lung viral load. A cohort of infected neonates were allowed to mature to adulthood and reinfected. Pulmonary function, BALF cellularity and cytokines, and T cell profiles were measured at 6 days post reinfection.

Results: The rA2-19F strain in neonatal mice caused substantial lung pathology including interstitial inflammation and airway mucus production, while A2 caused minimal inflammation and mucus production. Pulmonary inflammation was characterized by enhanced Th2 and reduced Th1 and effector CD8 ${ }^{+} \mathrm{T}$ cells compared to A2. As with primary infection, reinfection with $\mathrm{rA2}-19 \mathrm{~F}$ induced similar but exaggerated Th2 and reduced Th1 and effector CD $8^{+} \mathrm{T}$ cell responses. These immune responses were associated with increased airway hyperreactivity, mucus hyperproduction and eosinophilia that was greater than that observed with A2 reinfection. Pulmonary viral load during primary infection was higher with $\mathrm{rA2}-19 \mathrm{~F}$ than A2.

Conclusions: Therefore, rA2-19F caused enhanced lung pathology and Th2 and reduced effector $\mathrm{CD} 8^{+} \mathrm{T}$ cell responses compared to A2 during initial infection in neonatal mice and these responses were exacerbated upon reinfection. The exact mechanism is unknown but appears to be associated with increased pulmonary viral load in rA2-19F vs. A2 infected neonatal lungs. The rA2-19F strain represents a better neonatal mouse model of RSV infection.

Keywords: RSV, Neonatal mouse model, rA2-19F

\footnotetext{
* Correspondence: scormier@uthsc.edu

'Department of Pediatrics, University of Tennessee Health Science Center, Memphis, TN, USA

${ }^{2}$ Children's Foundation Research Institute, Le Bonheur Children's Hospital, Memphis, TN, USA
}

\section{Biomed Central}

(c) 2016 You et al. This is an Open Access article distributed under the terms of the Creative Commons Attribution License (http://creativecommons.org/licenses/by/4.0), which permits unrestricted use, distribution, and reproduction in any medium, provided the original work is properly credited. The Creative Commons Public Domain Dedication waiver (http:// creativecommons.org/publicdomain/zero/1.0/) applies to the data made available in this article, unless otherwise stated. 


\section{Background}

Respiratory Syncytial Virus (RSV) is the number one cause of lower respiratory tract infection [1]. RSV is also among the most important pathogens responsible for childhood pneumonia [2]. It has been estimated that 2.1 million children in the United States alone require medical attention for RSV infection each year [3].

There is still no vaccine or specific anti-viral therapeutics available. Currently, only a humanized monoclonal antibody against the fusion (F) protein of RSV, Palivizumab, is approved for use for high-risk infants [4], and the antiviral Ribavirin, which has been used, is not specific for RSV and its efficacy is controversial [5]. An early attempt at developing a formalin-inactivated RSV vaccine failed tragically in the 1960s [6, 7]. The failure of this RSV vaccine highlighted our lack of knowledge of the interaction of RSV with the infant immune system.

Many animal models of RSV infection have been used to study the mechanisms of RSV pathogenesis in human infants [8]. Mouse models are particularly useful because of the many genetically modified strains and an abundance of molecular biology tools and reagents commercially available. Our laboratory and others have used neonatal mouse models of infection to more closely mimic the interaction between RSV and the human infant immune system [9-11]. It has been found that neonatal mice (i.e., $<7$ days of age) represent a more age-appropriate model to study RSV immunopathology. For example, neonatal mice mount a T-helper type 2 (Th2) response to RSV infection as do human infants [10]. Secondary infection of mice initially infected as neonates resulted in airway inflammation, mucus production, and breathing difficulty, all symptoms of human RSV disease [11]. Importantly, our laboratory has shown that mice infected with high doses of RSV as neonates are predisposed to develop pulmonary complications later in life, as is observed in humans $[9,12]$. However, the current mouse models of RSV infection still fall short of reproducing some of the pathologies seen in human infants such as interstitial pneumonitis and alveolitis [13], which is believed to be due to the fact that mice are only semisusceptible to human RSV infection [14].

The need for a better mouse model of RSV infection has also led to identification of RSV strains that induce symptoms in mice more consistent with those of humans. The Long and A2 strains (originally isolated from clinical samples in 1957 and 1961, respectively) have long been the standard laboratory RSV strains used in research $[15,16]$. However, these historical strains induce less pathology in adult mice compared to more recently isolated strains, including the Line 19 strain $[17,18]$. Fusion (F) protein diversity has been shown to be an important factor responsible for pulmonary disease severity in adult mice [17]. Recently, a chimeric RSV in which the F protein from A2 strain was replaced with the $\mathrm{F}$ protein from the Line 19 strain (rA2-19F) was produced [17]. Infection of adult mice with rA2-19F resulted in higher pulmonary viral loads compared to either of its parent strains (A2 or line 19) [17]. In an effort to generate a better neonatal mouse model of RSV infection, we show here that neonatal mice infected with the chimeric rA2-19F strain of RSV, compared to the standard A2 strain, exhibited enhanced lung pathology, including interstitial pneumonitis and alveolitis, enhanced Th2 responses, and reduced effector $\mathrm{CD}^{+} \mathrm{T}$ cells during both primary and secondary infections. The enhanced pathology and aberrant immune responses correlated with higher pulmonary viral load in the neonatal lungs during primary infection.

\section{Materials and methods \\ Mice}

BALB/c breeders were purchased from Harlan Laboratories (Indianapolis, IN, USA) and bred in specific-pathogen-free facilities at University of Tennessee Health Science Center (UTHSC, Memphis, TN, USA). Pups born on the same date were used for experiments.

All animal experiments were performed according to the Guide for the Care and Use of Laboratory Animals and approved by the Institutional Animal Care and Use Committee at UTHSC.

\section{Viruses and the infection}

Human RSV A2 strain was purchased from Advanced Biotechnologies Inc (Columbia, MD, USA) and passaged in Vero cells (ATCC; Manassas, VA, USA) cultured in serum-free-media (SFM4MegaVir; Hyclone, Logan, UT, USA). The chimeric strain rA2-19F was a gift from Dr. Martin Moore (University of Emory, Atlanta, GA, USA) [17] and passaged in our laboratory as RSV A2 above.

Mice were infected intranasally with RSV at a dose of $10^{4.68} \mathrm{TCID}_{50}$ (tissue culture infectious dose) per gram of body weight. Sham mice were inoculated with culture media collected in the same way as virus stocks.

\section{Pulmonary viral load}

At various time points after primary RSV infection, lungs were isolated and stored at $-80{ }^{\circ} \mathrm{C}$ until viral load analysis by either RT-qPCR [19] or $\operatorname{TCID}_{50}[20,21]$ methods. For real time qPCR, total RNA was isolated from lungs using Qiagen RNeasy plus mini kit (Valencia, CA, USA); and one step RT-qPCR was performed using SuperScript ${ }^{\circ}$ III Platinum ${ }^{\circ}$ One-Step qRT-PCR Kit from Life Technologies (Carlsbad, CA, USA). Relative expression of the virus NS1 gene in lungs was normalized to Hprt using $\Delta \Delta \mathrm{Ct}$ method and the primers used were:

NS1, forward: 5' -CACAACAATGCCAGTGCTACAA-3'

NS1, reverse: 5'-TTAGACCATTAGGTTGAGAGCAA TGT-3' 
Hprt, forward: 5' -GGCTCCGTTATGGCGACCCG-3 Hprt, reverse: 5' -CGAGCAAGACGTTCAGTCCTGT CC-3'

For $\mathrm{TCID}_{50}$ assay, lungs were homogenized and supernatants were used to infect Vero cells on a 96-well plate. After incubation in $37^{\circ} \mathrm{C}$ at $5 \% \mathrm{CO}_{2}$ for 7 days, the wells showing cytopathic effect were counted and $\mathrm{TCID}_{50}$ calculated as per the Spearman-Kärber method [20, 21].

\section{Bronchoalveolar lavage fluid cellularity}

Bronchoalveolar lavage fluid (BALF) was isolated in $0.25 \mathrm{ml}$ (neonates) or $1 \mathrm{ml}$ (adults) of PBS containing $0.5 \%$ BSA. BALF cells were enumerated, spun onto slides, and stained with Hema-3 staining kit (Thermo Fisher Scientific, Waltham, MA, USA). Two unbiased observers differentiated the cellularity using standard morphological criteria. Supernatants were collected and stored at $-80{ }^{\circ} \mathrm{C}$ till cytokine analysis.

\section{Pulmonary $\mathrm{T}$ cell profile}

Lung single cells were prepared using gentleMACS ${ }^{\mathrm{mm}}$ Octo Dissociator (Miltenyi Biotec, San Diego, CA, USA). After red blood cell lysis, the cells were stimulated for $5 \mathrm{~h}$ with $5 \mathrm{ng} / \mathrm{ml}$ phorbol-12-myristate-13-acetate (PMA) and $500 \mathrm{ng} / \mathrm{ml}$ ionomycin (Sigma-Aldrich, St. Louis, MO) in the presence of GolgiPlug $\left(1 \mu \mathrm{l} / 10^{6}\right.$ cells; BD Biosciences, Franklin Lakes, NJ). After stimulation, the cells were stained with fixable viability dye and antibodies to CD3 (17A2), CD4 (RM4-4; Biolegend, San Diego, CA, USA), CD8 (53-6.7), IFNY (XMG1.2), and IL4 (BVD624G2). Stained cells were analyzed on a Canto II flow cytometer (BD Biosciences) and plotted with FlowJo software (v10 for Windows; Tree Star; Ashland, OR, USA). All antibodies and viability dye were from eBioscience (San Diego, CA, USA) unless otherwise stated.

\section{Lung histopathology}

Lungs were inflated at a constant fluid pressure of $25 \mathrm{~cm}$ and fixed with zinc formalin (Thermo Fisher Scientific). After fixation, lungs were embedded and sections cut and stained by the pathology core at UTHSC. Hematoxylin and eosin (H\&E) were used to identify cellular infiltrates and periodic acid-Schiff (PAS) for mucus in the airway epithelial cells.

\section{Pulmonary function}

Airway resistance to methacholine (MeCh; SigmaAldrich) was measured using the FlexiVent FX system (Scireq, Montreal, QC, Canada). Raw data were collected by fitting into a single -compartment model and normalized by subtracting individual baseline values at $0 \mathrm{mg} / \mathrm{ml} \mathrm{MeCh}$.

\section{Cytokine levels in the airways or the lung}

The kinetics of IL13 expression in the lung after primary infection was measured using real-time qPCR. Total lung RNA was isolated using Qiagen RNeasy plus mini kit and reverse-transcribed to cDNA using SuperScript III first-strand synthesis system. Real-time PCR was then performed using Power Sybr green PCR master mix (Life Technologies) and the relative expression of IL13 were normalized to Hprt using $\Delta \Delta \mathrm{Ct}$ method. The primers for IL13 were as follows and the primers for Hprt were as above.

Forward primer: 5' -TGATGAGCTACTACTGGTCAGC-3'

Reverse primer: 5'-GATCTCTTAGCACAAGGATG GC-3'

The level of other cytokines in the BALF including IFNy, IL12 (p40), and IL4 were measured using Milliplex mouse cytokine/chemokine assay kit (Millipore Corporation; Billerica, MA, USA) on Luminex 200 system (Luminex, Austin, TX, USA). IL13 level in the BALF were measured by ELISA kit from eBioscience following manufacturer's instructions. Data below detection limit of each cytokine were excluded.

\section{Statistical analysis}

Data were plotted as means \pm standard errors (SEM) by Prism 6 (GraphPad Software; La Jolla, CA, USA). Pulmonary function test results were analyzed using two-way analysis of variance and Bonferroni post-hoc tests. All other data were analyzed using Student's $t$-test (2 groups) or multiple $t$ test with Holm-Sidak correction (3 groups). Differences were considered significant if $p<0.05$. Every experiment was repeated at least twice.

\section{Results}

Primary rA2-19F infection induced higher pulmonary viral loads than $A 2$ and line 19

Human infant data demonstrate a positive correlation between RSV viral load and disease severity [22, 23]; and infection of adult mice with rA2-19F resulted in higher pulmonary viral loads compared to either of its parent strains (A2 or line 19) in the lung [17]. We therefore tested if this correlation stayed true in neonatal mice. To test this, pups were infected with rA2-19F, and pulmonary viral load was measured at various time points after infection by either real-time PCR (Fig. 1a) or TCID assay (Fig. 1b). This confirmed that peak viral load occurred at 4 days post-infection (dpi) in neonatal mice infected with rA2-19F, as in neonates infected with A2 [24] or line 19 [25]. We then compared the peak viral load at $4 \mathrm{dpi}$ in neonatal mice infected with A2, line 19, or $\mathrm{rA2}-19 \mathrm{~F}$. $\mathrm{TCID}_{50}$ assay shows that more live viruses were present in $\mathrm{rA2}-19 \mathrm{~F}$ than A2 or line 19 infected lungs (Fig. 1c; $12,247 \pm 2,321$ vs. $5,804 \pm 719$ or $3,795 \pm 309$ $\mathrm{TCID}_{50} / \mathrm{g}$ lung, respectively). Real-time PCR confirms that 


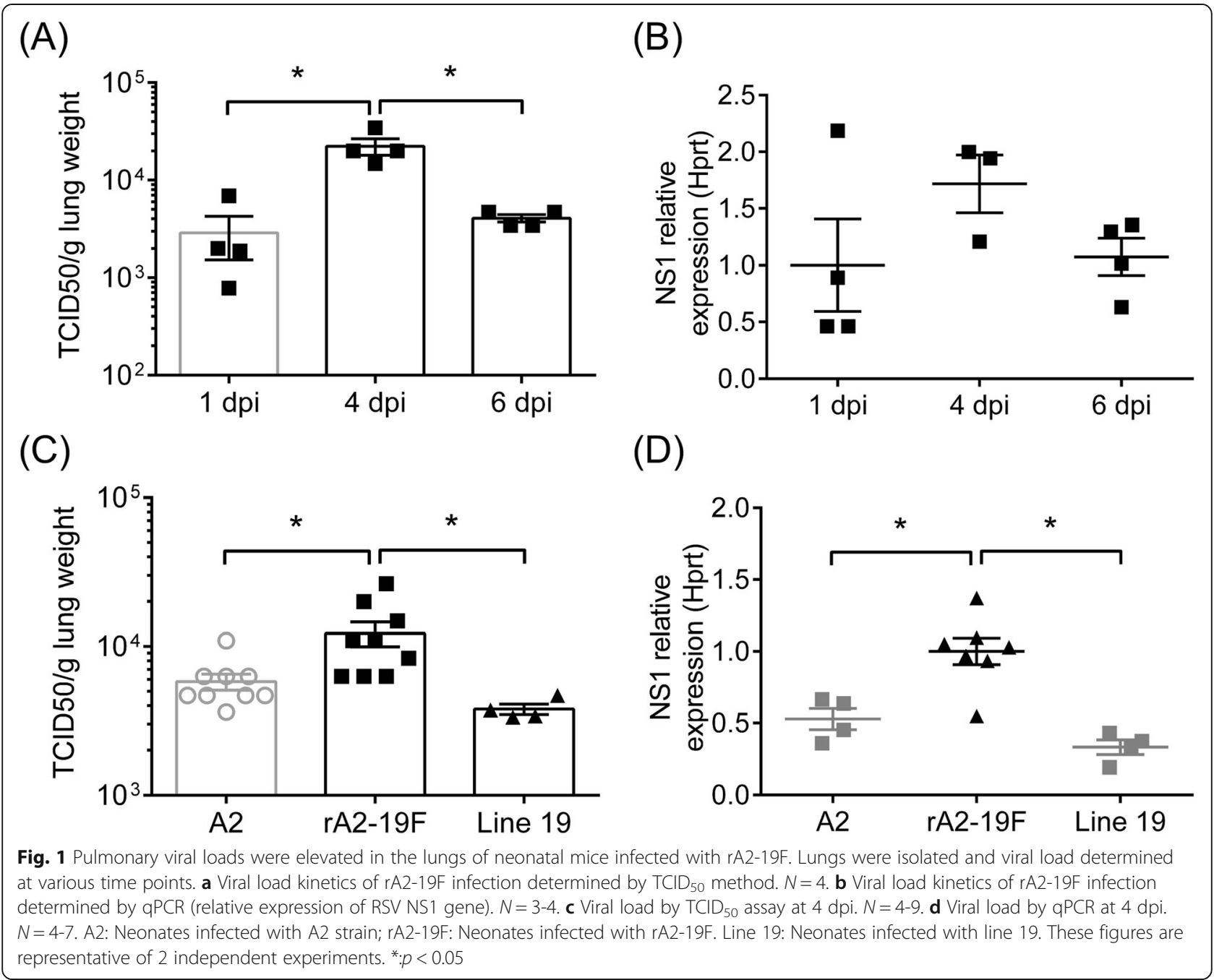

the relative expression of the virus NS1 gene was significantly higher in rA2-19F compared to A2 or line 19 infected lungs (Fig. $1 \mathrm{~d} ; 1.00 \pm 0.09$ vs. $0.53 \pm 0.07$ or $0.33 \pm$ 0.05 , respectively). No differences in pulmonary viral loads were observed between A2 and line 19 infected neonates. Since our hypothesis was that an RSV strain demonstrating higher viral load would more closely mimic human disease and since human infant data demonstrate a positive correlation between RSV viral load and disease severity, line 19 was not included in the rest of the study.

\section{Primary rA2-19F infection caused more lung pathology than $\mathrm{A} 2$ in neonates}

Lung pathology is the most direct method to measure severity of infection; therefore, we performed histological examination on the lungs isolated from pups infected with media (Sham), rA2-19F, or A2. As shown in Fig. 2, five-day-old pups infected with rA2-19F exhibited substantial peribronchiolar and interstitial inflammation; whereas pups infected with A2 only showed mild inflammation at 6 dpi (Fig. 2b \& c). Infection with rA2-19F also induced mucus production in airway epithelial cells; whereas infection with A2 induced sporadic amounts of mucus in airway cells at $8 \mathrm{dpi}$ (Fig. 2e \& f). Sham mice showed no signs of inflammation or mucus production (Fig. 2a \& d).

\section{Primary rA2-19F infection induced aberrant immune responses in the neonatal lung} Immunopathologies (i.e., Th2 biased immune responses) have been indicated in RSV-induced disease in both human [7] and animal studies [26]. We sought to determine if $\mathrm{rA2}-19 \mathrm{~F}$ infection recapitulated the typical immunopathologies associated with RSV in neonatal mice. To do this, pups were infected with either rA2$19 \mathrm{~F}$ or $\mathrm{A} 2$, and the pulmonary immune responses were determined at various time points post-infection. Both RSV infections induced macrophages, neutrophils, 


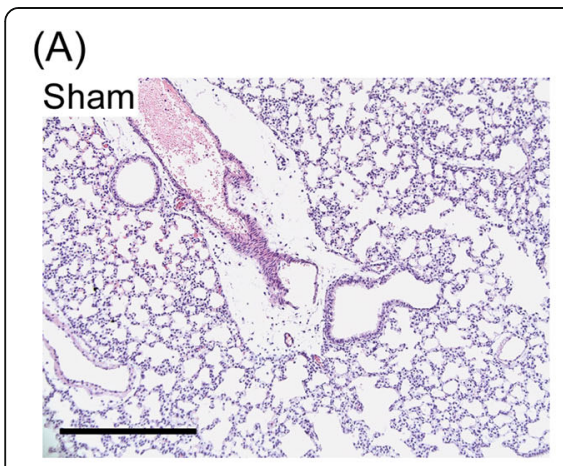

(D)

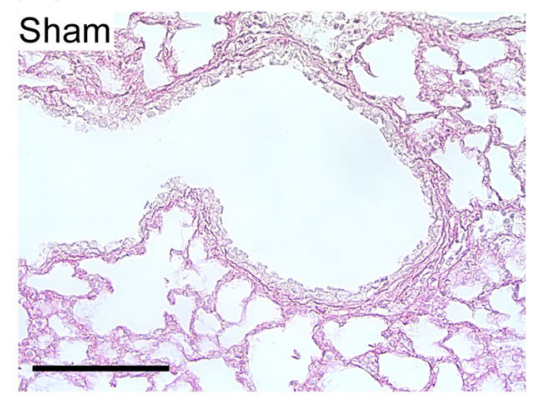

(B)

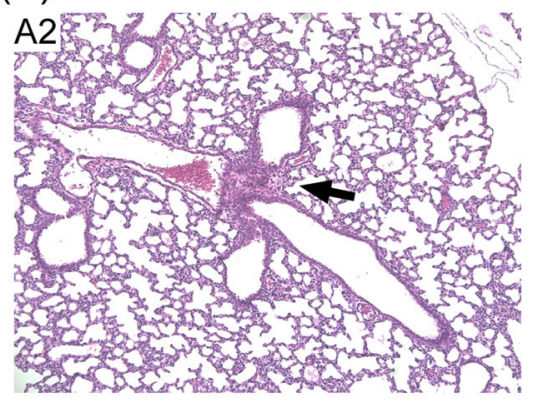

(E)

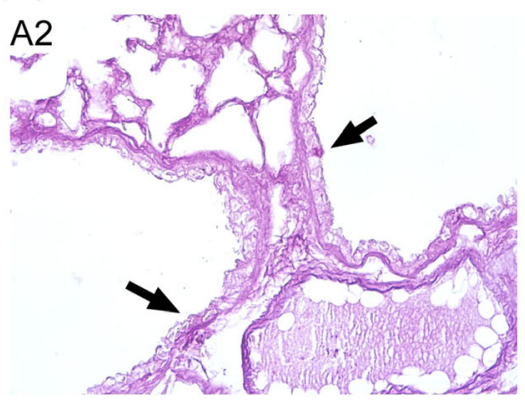

(C)

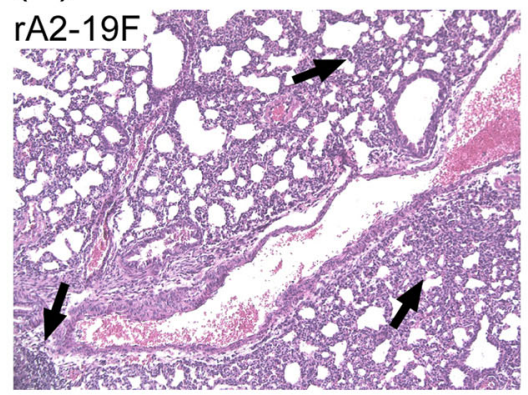

(F)

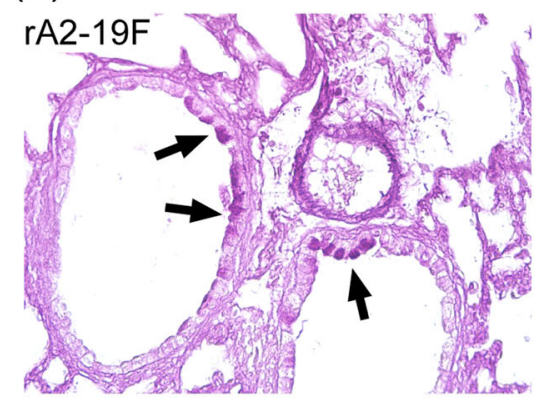

Fig. 2 Neonatal infection with rA2-19F induced significant lung pathology. Five-day old pups were infected with media, rA2-19F or A2, and lungs were isolated, fixed, and stained. a-c H\&E staining for inflammation at 6 dpi. Scale bar $=400 u m$. Arrows indicate inflammation. d-e PAS staining for airway mucus production at 8 dpi. Scale bar = 100 um. Arrows indicate mucus producing cells. Sham: Neonates infected with media; A2: Neonates infected with A2 strain; rA2-19F: Neonates infected with rA2-19F. These pictures are representative of 2 independent experiments; 3 mice per experiment time point

lymphocytes, and eosinophils into the bronchoalveolar lavage fluid (BALF; Fig. 3d -f: Sham vs. A2 or rA2-19F). We observed an increase in the frequency of lymphocytes at 6 dpi (Fig. 3b \& c; $1.37 \pm 0.19$ vs. $0.45 \pm 0.91 \%$ ) and eosinophils at $8 \mathrm{dpi}(1.71 \pm 0.29$ vs. $1.34 \pm 0.44 \%)$ in neonates infected with rA2-19F compared to A2. The numbers of lymphocytes (Fig. 3e \& f; $605 \pm 82$ vs. $224 \pm 55$ cells $/ \mathrm{ml})$ and eosinophils ( $898 \pm 211$ vs. $317 \pm 83$ cells $/ \mathrm{ml})$ were consistently increased. No differences were observed between the two groups at $3 \mathrm{dpi}$ in either cell frequencies (Fig. 3a) or numbers (Fig. 3d).

To further delineate the $\mathrm{T}$ cell populations in the lung, we measured the pulmonary $\mathrm{T}$ cell profile at $6 \mathrm{dpi}$ using flow cytometry (Fig. 4; gating strategy refers to Additional file 1: Figure S1). Primary RSV infection of neonates induced both Th1 and Th2 cells in the lung (Sham vs. A2 or rA2-19F). However, the frequency of IL4 expressing CD $4^{+}$ $\mathrm{T}$ cells $(0.28 \pm 0.01$ vs. $0.20 \pm 0.02 \%)$ cells was greater and the frequency of IFN $\gamma$ expressing $\mathrm{CD}^{+} \mathrm{T}$ cells $(0.66 \pm$ 0.06 vs. $0.91 \pm 0.10 \%$ ) was lower in the lungs of rA2-19F vs. A2 infected mice (Fig. 4a). The IL4 expressing CD4 ${ }^{+} \mathrm{T}$ cells appear to be Th2 cells $\left(\mathrm{CD} 4^{+} \mathrm{IFN}^{-} \mathrm{IL}^{+}{ }^{+}\right.$), while the IFN $\gamma$ expressing $\mathrm{CD}^{+}{ }^{+} \mathrm{T}$ cells appear to be mainly Th1 cells $\left(\mathrm{CD}^{+} \mathrm{IFN}^{+}{ }^{+} \mathrm{IL}^{-}\right)$(Fig. 4b,c). Few multi-functional
T cells $\left(\mathrm{CD}_{4}^{+} \mathrm{IFN}^{+} \mathrm{IL}^{+}\right.$and $\left.\mathrm{CD}^{+} \mathrm{IFN}^{+}{ }^{+} \mathrm{IL}^{+}\right)$were found in the neonatal lung (Fig. 4b, c, d, e). Additionally, a reduced frequency of effector $\mathrm{CD} 8^{+} \mathrm{T}$ cells $\left(\mathrm{CD}^{+} \mathrm{IFN}^{+}\right)$ were found in rA2-19F compared to A2 infected lungs (14.18 \pm 1.20 vs. $17.56 \pm 0.75 \%$ ) (Fig. $4 \mathrm{~d} \&$ e).

\section{Primary rA2-19F infection induced more pulmonary IL13 expression than $\mathrm{A} 2$ in neonates}

Both human [27, 28] and animal model [26] studies have demonstrated that Th2 biased immune responses during RSV infection play a pathogenic role. Our lab has published several reports $[29,30]$ showing that pulmonary $\mathrm{T}$ cells (and other cells) in neonatal mice express elevated levels of IL4R $\alpha$, a component of the receptor for both IL4 and IL13, than adult mice; and the downregulation of pulmonary IL4R $\alpha$ expression or deletion of IL4R $\alpha$ specifically on $\mathrm{CD} 4^{+} \mathrm{T}$ cells substantially ablated the pathophysiologies associated with both primary and secondary RSV infection in mice initially infected as neonates. We hypothesized that rA2-19F might exacerbate lung pathologies via the same mechanism (i.e., elevating IL4R $\alpha$ levels or signaling). Therefore, we measured the expression of IL4R $\alpha$ (receptor) on $\mathrm{CD}_{4}^{+} \mathrm{T}$ cells by flow cytometry and IL13 (ligand) expression in the lung by 


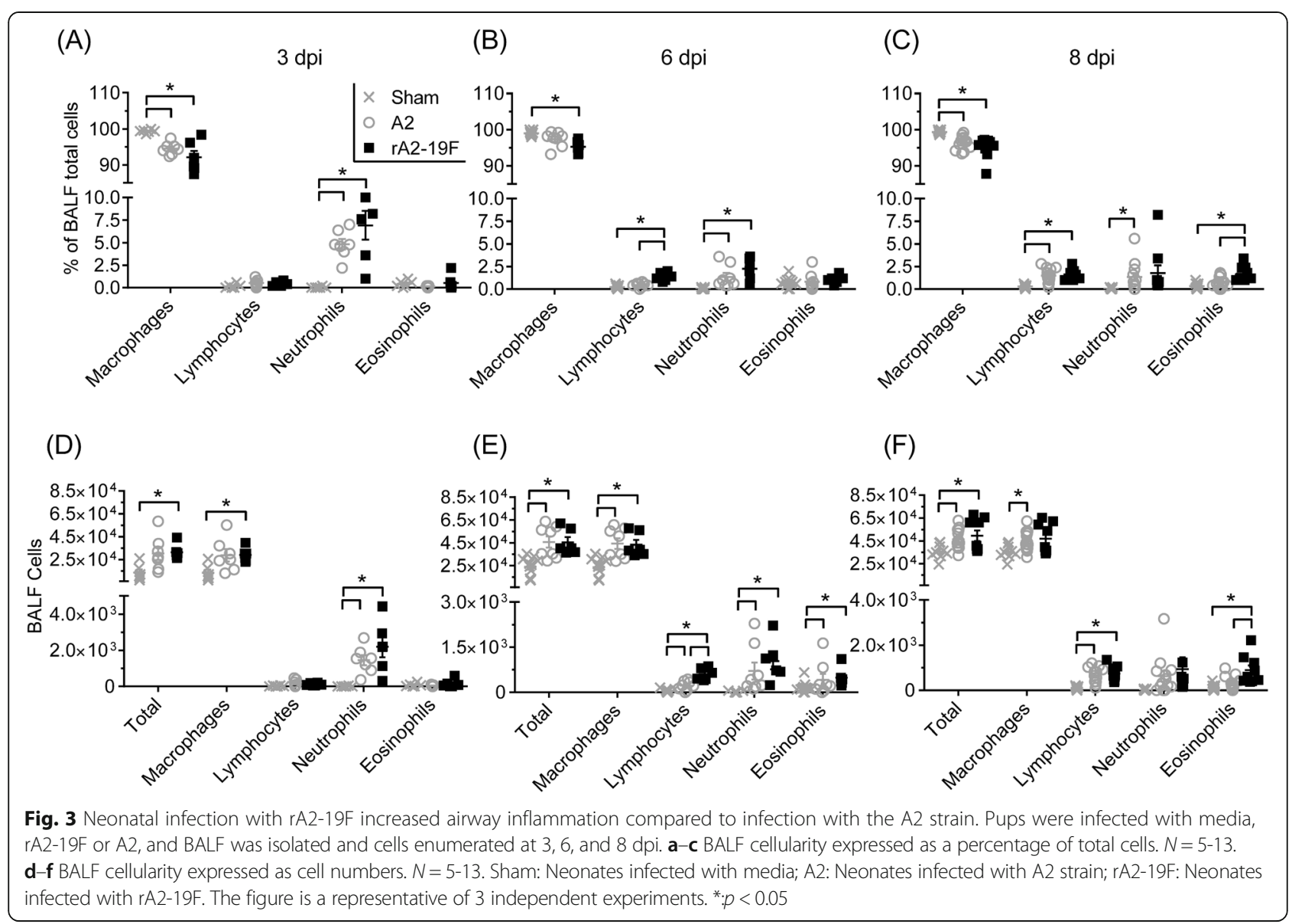

real-time PCR during primary infection. No significant differences were detected in IL4R $\alpha$ expression on $C D 4^{+}$ $\mathrm{T}$ cells or its subtypes between $\mathrm{rA2}-19 \mathrm{~F}$ and A2 infected lungs (6 dpi, Fig. 5a-c). However, IL13 expression was significantly increased in rA2-19F infected mouse lungs compared to A2 infected lungs at 6 dpi (Fig. 5d; $35.22 \pm$ 14.14 vs. $6.58 \pm 2.64$ ). This increase in IL13 expression at $6 \mathrm{dpi}$ is consistent with the observation that Th2 cells were increased at this same time point in rA2-19F compared to A2 infected mice (Fig. 4).

\section{Lung pathology was exacerbated following secondary infection with $\mathrm{rA2}-19 \mathrm{~F}$}

The failed vaccine trial in the 1960s showed that RSV-FI vaccinated infants developed more severe lung disease than the placebo during natural RSV infection [7]. Therefore, we and others $[10,24,31]$ utilize an RSV reinfection model to model this phenomenon. This model has effectively demonstrated that RSV infects and replicates in the lung [11] and induces substantial pulmonary pathophysiologies following reinfection [10, 24, 31].
To determine if rA2-19F further exacerbated lung pathologies during reinfection, pups were infected with either $\mathrm{rA2}-19 \mathrm{~F}$ or A2 and reinfected with the same virus strain at 4 weeks post-primary infection. As illustrated in Fig. 6, both A2 and rA2-19F reinfected mice showed greater airway resistance than sham infected or single infected mice. However, airway resistance in rA2-19F reinfected mice was significantly greater than A2 reinfected mice ( $4.67 \pm 1.54$ vs. $2.44 \pm 0.56 \mathrm{~cm} \mathrm{H} 2 \mathrm{O} \cdot \mathrm{s} / \mathrm{ml})$.

Histological examination of the lungs confirmed that overall pulmonary inflammation appeared similar between the two groups (Fig. 7b \& c); whereas rA2-19F reinfection induced greater airway mucus production compared to A2 reinfected lungs (Fig. 7e \& f). No inflammation and mucus production was obvious in sham infected mice (Fig. 7a \& d).

\section{Secondary rA2-19F infection exacerbated the aberrant im-} mune responses

As shown above, rA2-19F reinfection caused similar inflammation as A2 in the lung; and we further determined 


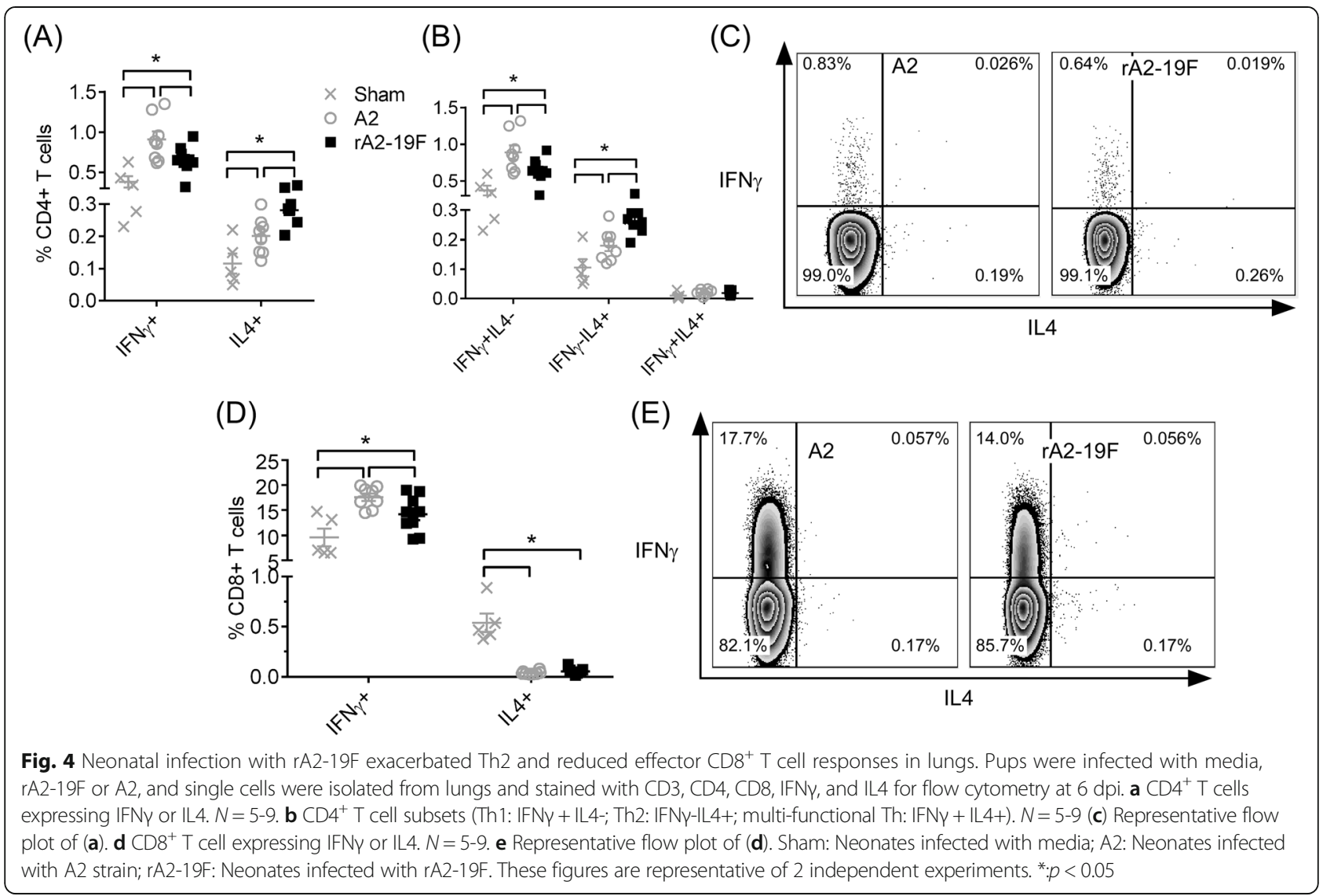

the types of these inflammatory cells by measuring BALF cellularity and pulmonary T cell profiles. Our data from the BALF (Fig. 8) show that reinfection recruited lymphocytes, neutrophils, and eosinophils into the lungs. Specifically, rA2-19F reinfection increased eosinophil recruitment into the airways as evidenced by increased percentages $(12.23 \pm 3.75$ vs. $3.88 \pm 1.06 \%)$ and numbers $(44,005 \pm 19,218$ vs. $7,531 \pm 2,216$ cells $/ \mathrm{ml})$ compared to A2 reinfection. No significant changes were observed in any other cell types, including monocytes/macrophages, lymphocytes, or neutrophils.

While no significant changes were observed in the total $\mathrm{CD}^{+} \mathrm{T}$ cell population (data not shown), the types of these $\mathrm{T}$ cells in the lung differed between $\mathrm{rA2}-19 \mathrm{~F}$ and A2 reinfected mice (Fig. 9a-e). Consistent with the observation at primary infection (Fig. 4), rA2-19F reinfection increased the frequency of IL4 expressing $\mathrm{CD}^{+} \mathrm{T}$ cells $(15.54 \pm 1.70$ vs. $8.33 \pm 0.82 \%)$ and decreased the frequency of IFN $\gamma$ expressing $\mathrm{CD}^{+} \mathrm{T}$ cells $(31.46 \pm 2.41 \mathrm{vs}$ $48.08 \pm 3.24 \%)$. Specifically, frequencies of both Th2 cells $\left(\mathrm{CD} 4{ }^{+}\right.$IFN $\left.\gamma-\mathrm{IL} 4^{+}\right)$and multifunctional Th cells $\left(\mathrm{CD} 4^{+}\right.$ $\mathrm{IFN}^{+}{ }^{+} \mathrm{IL}^{+}{ }^{+}$) were increased in rA2-19F vs. A2 reinfected mice. Furthermore, less effector $\mathrm{CD}^{+} \mathrm{T}$ cells $\left(\mathrm{CD} 8^{+}\right.$
IFN $\gamma^{+}$) were observed in rA2-19F compared to A2 reinfected lungs ( $57.47 \pm 2.87$ vs. $72.85 \pm 3.74 \%$ ).

Cytokine levels in the BALF were also consistent with above $\mathrm{T}$ cell observations (Fig. 9f-i). Less type I cytokines (IFN $\gamma$ and IL12p40) and more type II cytokine (IL13) were detected in the BALF from mice reinfected with $\mathrm{rA2}-19 \mathrm{~F}$ vs. A2. Specifically, IFN $\gamma$ responses $(24.11 \pm 5.85$ vs $70.55 \pm 12.08 \mathrm{pg} / \mathrm{ml})$ and IL12p40 ( $5.97 \pm 0.76$ vs. $15.45 \pm 2.81 \mathrm{pg} / \mathrm{ml}$ ) were reduced by almost 3 fold and IL13 $(33.36 \pm 3.23$ vs. $22.15 \pm 2.50 \mathrm{pg} /$ $\mathrm{ml}$ ) were increased by approximately $50 \%$ in $\mathrm{rA2}-19 \mathrm{~F} /$ rA2-19F vs. A2/A2 mice. No difference was observed in levels of IL4 between these two groups.

\section{Discussion}

The current neonatal mouse model of infant RSV disease was established by our laboratories and other groups [9-11, 24], in which neonatal ( $<7 \mathrm{~d}$ old) BALB/c mice are infected with the standard laboratory strain A2. Here, we established a new neonatal mouse model using the chimeric RSV (rA2-19F) in which the F protein from the A2 strain was replaced with the $F$ protein from line 19 clinical isolate [17]. The infection of 5 days old 


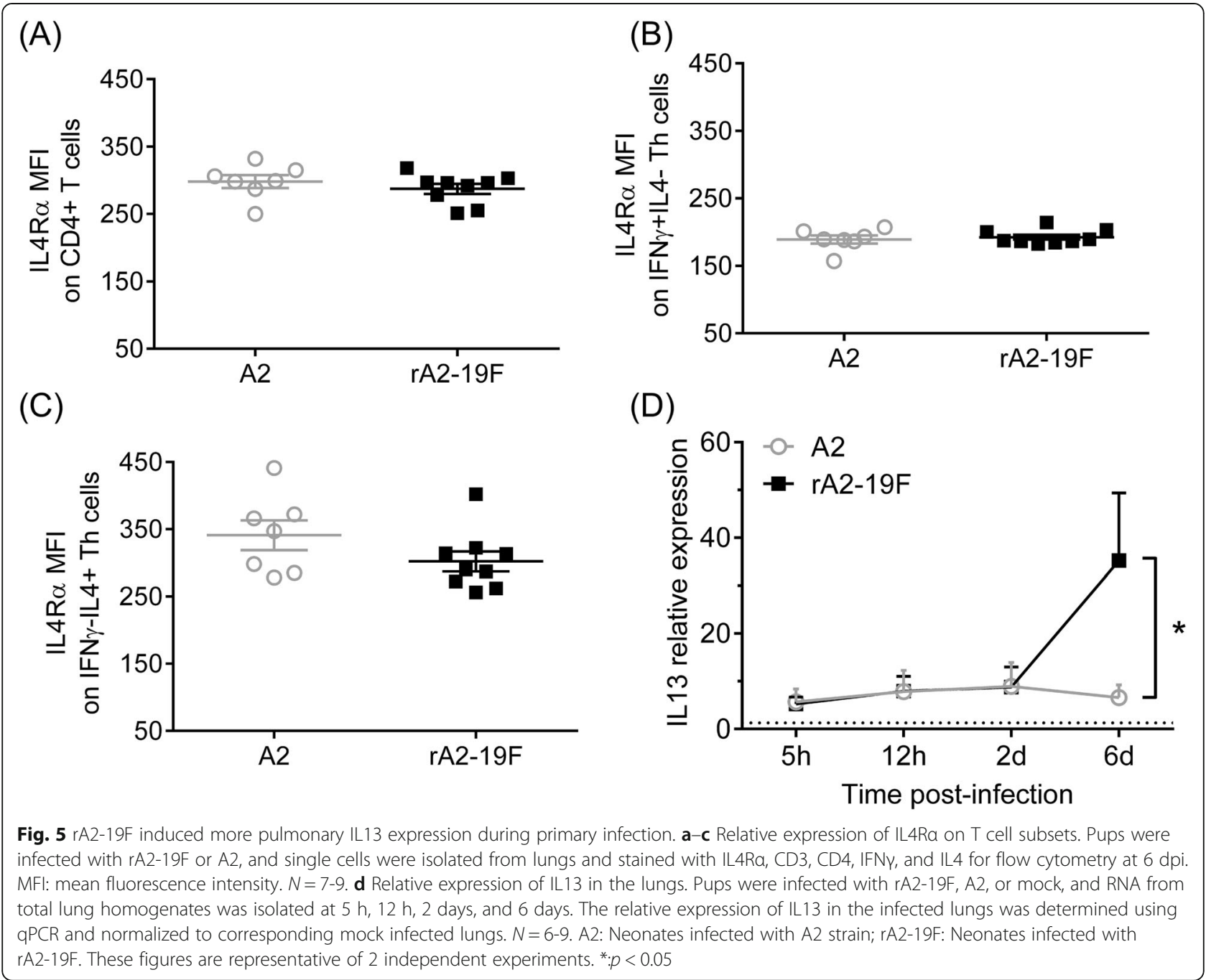

BALB/c pups with rA2-19F induced less frequencies of Th1, less effector $\mathrm{CD}^{+} \mathrm{T}$, and more Th2 cells in the lung compared to A2. The aberrant immune response was accompanied with severe lung injury characterized with significant interstitial and alveolar inflammation, airway mucus production and eosinophilia, and IL13 expression in lung homogenates. Upon reinfection, mice exhibited increased airway hyperreactivity, mucus hyperproduction, and eosinophilia with rA2-19F compared to A2. Consistently, mice reinfected with rA2-19F exhibited increased Th2 and decreased Th1 and effector $\mathrm{CD}^{+} \mathrm{T}$ cells in lungs with increased type 2 cytokine (IL13) and decreased type 1 cytokines (IFNy and IL12p40) in airways compared to mice reinfected with A2.

Although it is out of the scope of this study, a possible mechanism that rA2-19F enhanced lung pathology and induced aberrant immune responses (increased Th2 and decreased Th1 and effector $\mathrm{CD}^{+} \mathrm{T}$ cells) compared to the A2 strain is that $\mathrm{rA2}-19 \mathrm{~F}$ induces a more productive infection resulting in enhanced viral replication and higher pulmonary viral loads. Our data presented here in neonates agree with data presented by Dr. Moore's group, which showed that higher pulmonary viral loads are observed in adult mice infected with rA2-19F compared to A2 or line 19 [17]. Further studies by this same group demonstrated that the F protein from line 19, and thus, in rA2-19F has a higher fusion activity compared to the F protein from A2 [32]. We believe the same to be true here; the $\mathrm{F}$ protein results in higher fusion activity in neonates and this results in elevated pulmonary viral loads.

The new neonatal mouse model presented here is an improved model due to the fact that primary infection with rA2-19F more closely mimics infection in human infection in infants compared to the A2 strain. In human 


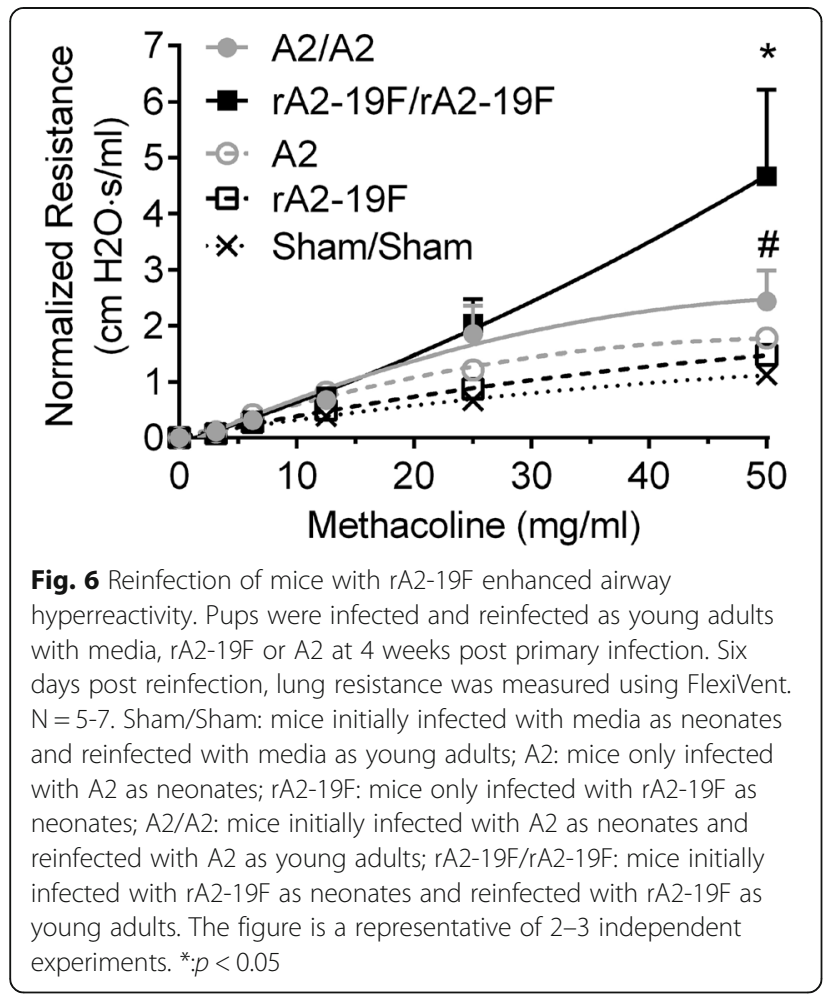

infants, severe RSV infection causes substantial lung damage, including bronchiolitis and interstitial pneumonia and airway obstruction due to mucus production and epithelial cell sloughing [13]. Infection with rA219F induced significant interstitial inflammation and airway mucus production, whereas A2 infection induced only mild inflammation and mucus production in neonatal mice. Additionally, the immune responses induced by rA2-19F in neonatal mice are consistent with the responses induced by natural severe RSV infections in human infants. The innate immune response induced by natural RSV infection in infants is characterized with neutrophil influx in the airways [33]. Infection of neonatal mice with either virus strain (rA2-19F or A2) induced a significant influx of neutrophils into the airways compared to sham mice, while rA2-19F resulted in an enhanced, although not significant, recruitment compared to A2. The adaptive immune response during human infant RSV infection is generally Th2 biased [26-28]. Moreover, $\mathrm{CD}^{+} \mathrm{T}$ cells are thought to be protective in infants, since a lack of pulmonary $\mathrm{CD} 8^{+} \mathrm{T}$ cells is observed in fatal cases of RSV infection [34]. In this new model, primary infection of neonatal mice with

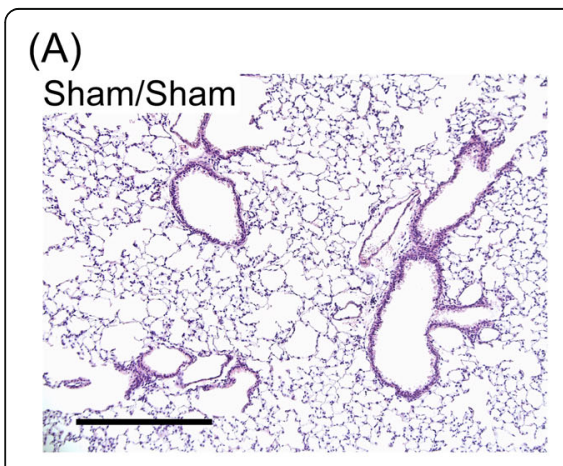

(D)

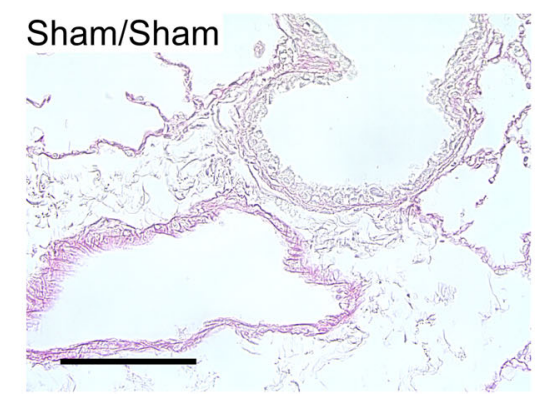

(B)

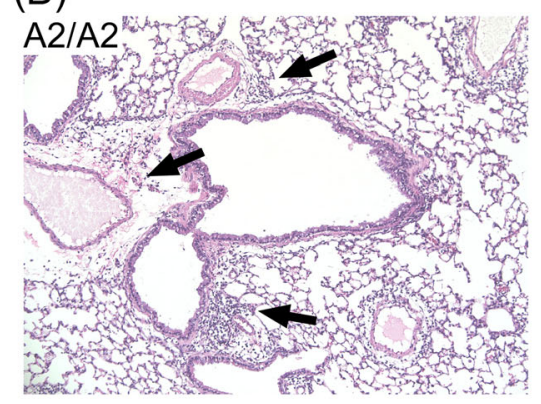

(E)

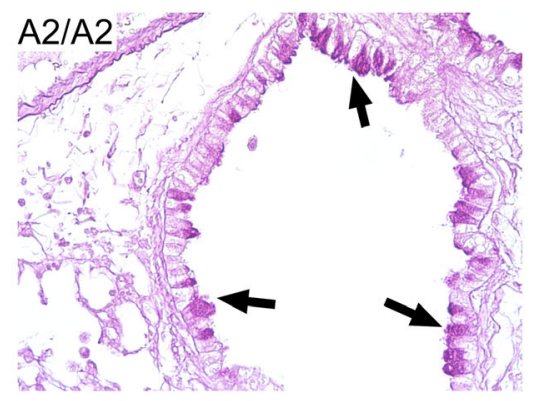

(C)

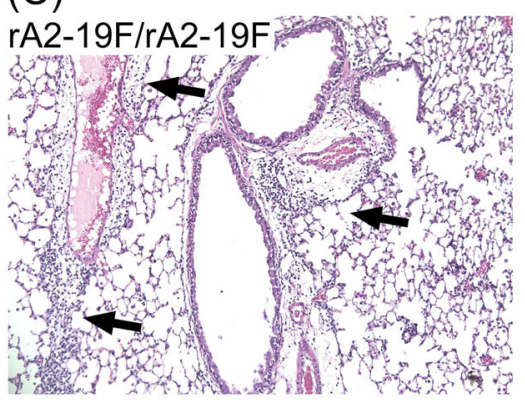

(F)

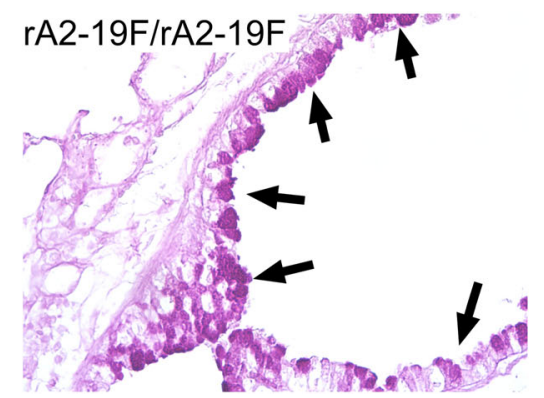

Fig. 7 Reinfection of rA2-19F worsened lung pathology. Pups were infected and reinfected as young adults with media, rA2-19F or A2. Six days post reinfection, lungs were isolated, fixed, and stained for histopathology. a-c H\&E staining for inflammation. Scale bar $=100 u m$. Arrows indicate inflammatory cell aggregates. d-f PAS staining for airway mucus production. Scale bar $=400$ um. Arrows indicate mucus producing cells. Sham/Sham: mice initially infected with media as neonates and reinfected with media as young adults; A2/A2: mice initially infected with A2 as neonates and reinfected with A2 as young adults; rA2-19F/rA2-19F: mice initially infected with rA2-19F as neonates and reinfected with rA2-19F as young adults. The figure is a representative of 2 independent experiments; 3 mice per experiment time point 


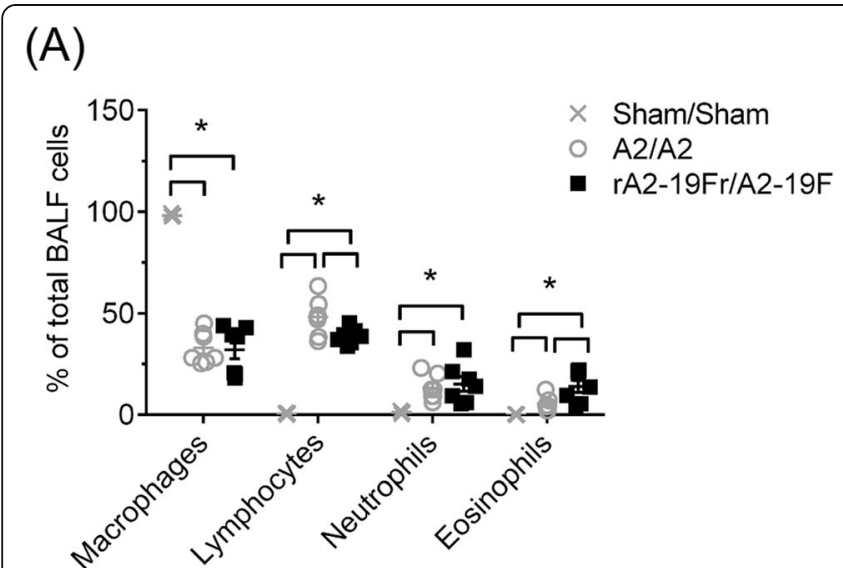

(B)

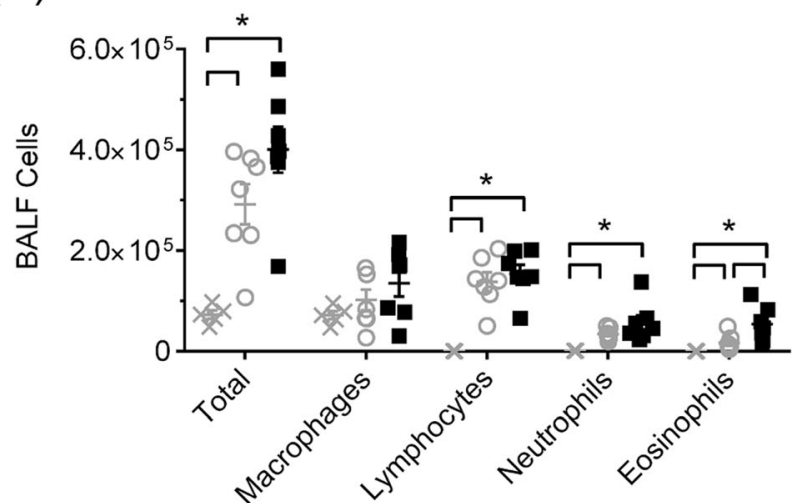

Fig. 8 Airway inflammation is increased following reinfection with rA2-19F. Pups were infected and reinfected as young adults with media, rA2-19F or A2. Six days post reinfection, BALF was isolated and enumerated. a BALF cellularity expressed as a percentage. $N=7$. $\mathbf{b} B A L F$ cellularity expressed as cell numbers. $N=5-7$. Sham/Sham: mice initially infected with media as neonates and reinfected with media as young adults; A2/A2: mice initially infected with A2 as neonates and reinfected with A2 as young adults; rA2-19F/rA2-19F: mice initially infected with rA2-19F as neonates and reinfected with $\mathrm{rA2}-19 \mathrm{~F}$ as young adults. The figure is a representative of $2-3$ independent experiments. ${ }^{*}: p<0.05$

rA2-19F induced a greater Th2 skewed response (higher frequency of Th2 cells, lower frequency of Th1 cells, and more IL13 expression) and further reductions in effector $\mathrm{CD}^{+} \mathrm{T}$ cell responses in the lungs compared to A2. The secondary immune responses to rA2-19F (i.e., reinfection) reflected the primary responses with an even stronger Th2 bias and further reduction of effector $\mathrm{CD}^{+} \mathrm{T}$ cells. These immune responses correlated to elevated airway hyperreactivity and mucus hyperproduction.

Recently, a manuscript using line 19 in neonatal mice was published [25]. This model successfully demonstrated that neonates infected with line 19 exhibit delayed and immature macrophage responses in the lung compared to adults and suggested that this deficiency in macrophage responses may explain RSV pathogenesis in infants. Similar to our data with A2 or rA2-19F compared to sham pups, Empey and colleagues observed a non-significant decrease in the percentage of BALF macrophages between mock pups and line 19 pups. Since we did not subphenotype the BALF macrophages, it is unclear, but highly likely that as with line 19 in neonatal mice, rA2-19F infection of neonatal mice results in an immature, delayed macrophage response. However, it is important to note that in our hands, pulmonary viral load following neonatal infection with $\mathrm{rA2}-19 \mathrm{~F}$ was greater than that with A2 or line 19 and that A2 infection resulted in similar viral loads as line 19. Disease severity in humans has been positively associated with viral load. Also similar to human disease, neonatal infection with rA2-19F significantly increased mucus production in the airways, airways disease as evidenced by pathology, and airways resistance compared to A2. This was accompanied by modest increases in lymphocytes and eosinophils during primary infection.

As with all models, limitations exist. Most animal models of RSV, except chimpanzees, suffer from the fact that they are only semi-susceptible to human RSV infection. Although the infection of neonatal mice with rA2-19F resulted in higher pulmonary viral loads compared to A2, the peak pulmonary viral load at 4 dpi was still significantly lower than the inoculum suggesting that rA2-19F infection is still not optimal in mouse lung cells. This may be due to the infection route. For example, the mice are infected by inhaling a bolus dose of RSV intranasally, while human infants are typically infected by inhalation or aerosolized virus. In the mouse, our data demonstrate that approximately $70 \%$ of the intranasally inhaled volume is directly delivered into the lung; however, the location where this distributes in the lung may not reflect that of a natural infection; and the resulting disease progression may be different.

\section{Conclusions}

In summary, we present a new neonatal mouse model of severe RSV infection in infants. In this model, rA219F infection in neonatal mice induced enhanced lung pathology (interstitial pneumonia and mucus hyperproduction), exaggerated Th2 bias, and reduced effector $\mathrm{CD}^{+} \mathrm{T}$ cells during both primary and secondary infections compared to the standard laboratory strain A2. In 


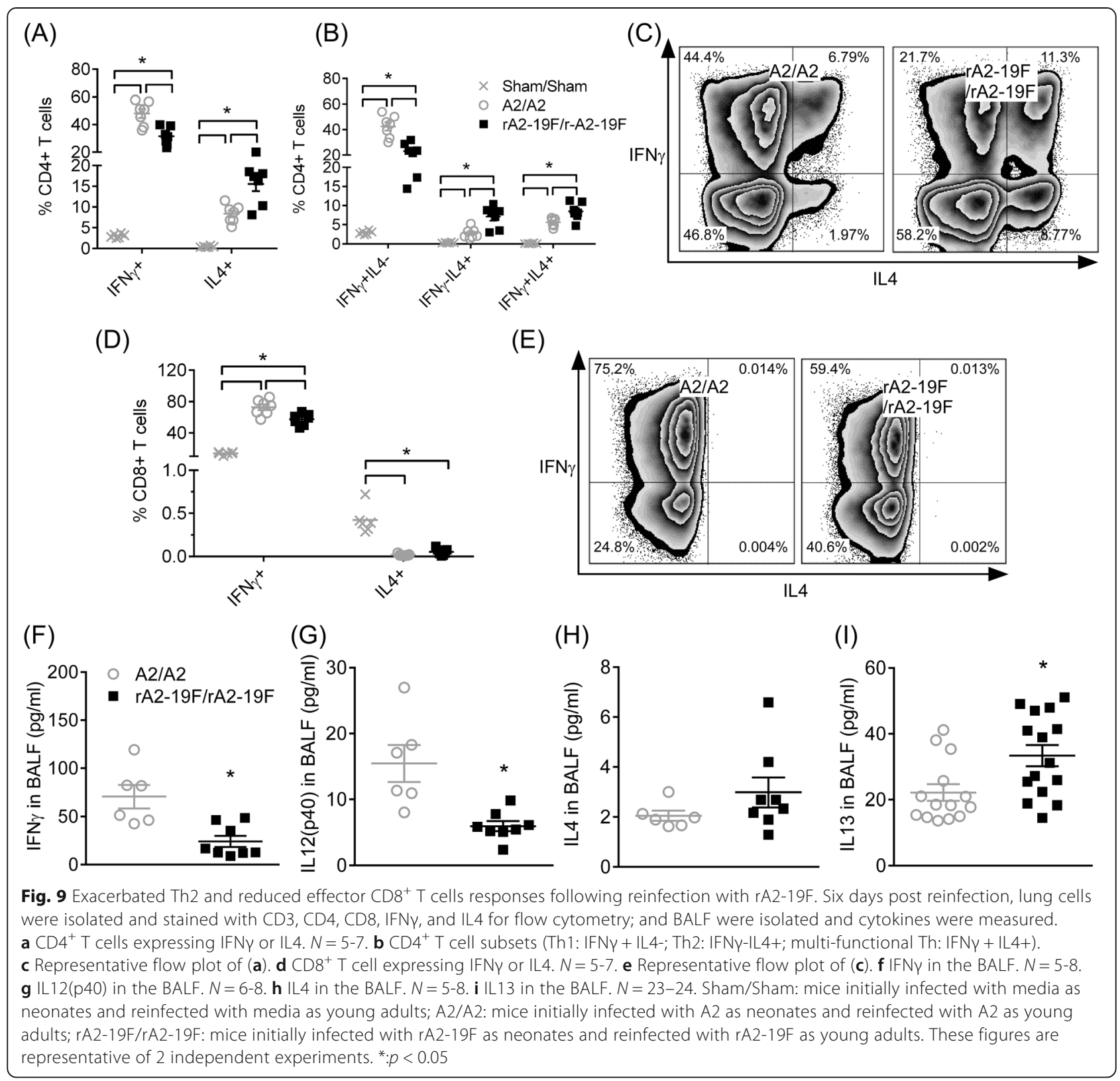

addition, rA2-19F resulted in a higher viral load in the neonatal lung compared to A2 during primary infection. These data suggest that rA2-19F infection in neonatal mice is a better mouse model for RSV infection in human infants.

\section{Additional file}

Additional file 1: Figure S1. Gating strategy for T cell subsets analysis. Live, $\mathrm{CD}^{+}$cells were first gated, then single, live, $\mathrm{CD}^{+}$cells in lymphocyte gate were selected. These $\mathrm{CD} 3^{+} \mathrm{T}$ cells were divided into $\mathrm{CD}^{+}$and $\mathrm{CD} 8^{+} \mathrm{T}$ cells subsets. Each subset were further classified into Th1 $\left(\mathrm{CD}^{+}{ }^{+} \mathrm{FNY}{ }^{+} \| \mathrm{L} 4-\right)$, Th2 $\left(\mathrm{CD} 4^{+}\right.$IFNY $\left.I L 4^{+}\right)$, multi-functional Th $\left(\mathrm{CD} 4^{+}\right.$ $\left.\mathrm{IFNY}{ }^{+} \| \mathrm{L}^{+}\right)$cells, TC1 $\left(\mathrm{CD} 8^{+} \mathrm{IFNY} \gamma^{+}\right)$and TC2 $\left(\mathrm{CD} 8^{+} \| 4^{+}\right)$cells.

\section{Abbreviations}

RSV: Respiratory syncytial virus; BALF: Bronchoalveolar lavage fluid; rA2-19F: The chimeric virus in which the $F$ protein from A2 strain was replaced with the $F$ protein from the line 19 strain.; Th1:T helper type 1; Th2: Thelper type 2; TCID 50 : Tissue culture infectious dose; PMA: Phorbol-12-myristate-13-acetate; H\&E: Hematoxylin and eosin; PAS: Periodic acid-Schiff; SEM: Standard errors; dpi: Days post-infection.

\section{Competing interests}

The authors declare that they have no competing interests.

\section{Authors' contributions}

DY designed the study, performed most of the experiments, and wrote the manuscript. DTS performed the BALF cellularity and IL-13 qPCR experiments and wrote the manuscript. BS performed the BALF cellularity and assisted in pulmonary function test. JS assisted in pulmonary function test. SAC conceived and designed the study and wrote the manuscript. All authors read and approved the final manuscript. 


\section{Acknowledgements}

The authors would like to thank Dr. Martin Moore (Emory University, Atlanta, Georgia) for providing the chimeric virus (rA2-19F) and for thoughtful discussions prior to and during the preparation of this manuscript. This study was supported by U.S. National Institutes of Health grants (R01Al090059, R01ES015050, and P42ES013648) to S.A.C.

\section{Received: 16 December 2014 Accepted: 29 June 2015}

Published online: 01 August 2015

\section{References}

1. Nair H, Nokes DJ, Gessner BD, Dherani M, Madhi SA, Singleton RJ, et al. Global burden of acute lower respiratory infections due to respiratory syncytial virus in young children: a systematic review and meta-analysis. Lancet. 2010;375:1545-55.

2. Rudan I, O'Brien KL, Nair H, Liu L, Theodoratou E, Qazi S, et al. Epidemiology and etiology of childhood pneumonia in 2010: estimates of incidence, severe morbidity, mortality, underlying risk factors and causative pathogens for 192 countries. J Glob Health. 2013;3:010401

3. Hall CB, Weinberg GA, Iwane MK, Blumkin AK, Edwards KM, Staat MA, et al. The burden of respiratory syncytial virus infection in young children. $N$ Engl J Med. 2009;360:588-98.

4. Palivizumab, a humanized respiratory syncytial virus monoclonal antibody, reduces hospitalization from respiratory syncytial virus infection in high-risk infants. The IMpact-RSV Study Group. Pediatrics. 1998;102:531-37.

5. Ventre K, Randolph AG. Ribavirin for respiratory syncytial virus infection of the lower respiratory tract in infants and young children. Cochrane Database Syst Rev. 2007:(1):CD000181.

6. Kapikian AZ, Mitchell RH, Chanock RM, Shvedoff RA, Stewart CE. An epidemiologic study of altered clinical reactivity to respiratory syncytial (RS) virus infection in children previously vaccinated with an inactivated RS virus vaccine. Am J Epidemiol. 1969;89:405-21.

7. Kim HW, Canchola JG, Brandt CD, Pyles G, Chanock RM, Jensen K, et al. Respiratory syncytial virus disease in infants despite prior administration of antigenic inactivated vaccine. Am J Epidemiol. 1969:89:422-34.

8. Byrd LG, Prince GA. Animal models of respiratory syncytial virus infection. Clin Infect Dis. 1997;25:1363-8.

9. You D, Becnel D, Wang K, Ripple M, Daly M, Cormier SA. Exposure of neonates to respiratory syncytial virus is critical in determining subsequent airway response in adults. Respir Res. 2006;7:107.

10. Culley FJ, Pollott J, Openshaw PJ. Age at first viral infection determines the pattern of T cell-mediated disease during reinfection in adulthood. J Exp Med. 2002;196:1381-6.

11. Dakhama A, Park JW, Taube C, Joetham A, Balhorn A, Miyahara N, et al. The enhancement or prevention of airway hyperresponsiveness during reinfection with respiratory syncytial virus is critically dependent on the age at first infection and IL-13 production. J Immunol. 2005;175:1876-83.

12. Becnel D, You D, Erskin J, Dimina DM, Cormier SA. A role for airway remodeling during respiratory syncytial virus infection. Respir Res. 2005;6:122.

13. Johnson JE, Gonzales RA, Olson SJ, Wright PF, Graham BS. The histopathology of fatal untreated human respiratory syncytial virus infection. Mod Pathol. 2007;20:108-19.

14. Bem RA, Domachowske JB, Rosenberg HF. Animal models of human respiratory syncytial virus disease. Am J Physiol Lung Cell Mol Physiol. 2011:301:L148-56.

15. Chanock R, Roizman B, Myers R. Recovery from infants with respiratory illness of a virus related to chimpanzee coryza agent (CCA). I. Isolation, properties and characterization. Am J Hyg. 1957;66:281-90.

16. Kapikian AZ, Bell JA, Mastrota FM, Johnson KM, Huebner RJ, Chanock RM. An outbreak of febrile illness and pneumonia associated with respiratory syncytial virus infection. Am J Hyg. 1961;74:234-48.

17. Moore ML, Chi MH, Luongo C, Lukacs NW, Polosukhin W, Huckabee MM, et al. A chimeric A2 strain of respiratory syncytial virus (RSV) with the fusion protein of RSV strain line 19 exhibits enhanced viral load, mucus, and airway dysfunction. J Virol. 2009;83:4185-94.

18. Lukacs NW, Moore ML, Rudd BD, Berlin AA, Collins RD, Olson SJ, et al. Differential immune responses and pulmonary pathophysiology are induced by two different strains of respiratory syncytial virus. Am J Pathol. 2006;169:977-86.
19. Boukhvalova MS, Yim KC, Prince GA, Blanco JC. Methods for monitoring dynamics of pulmonary RSV replication by viral culture and by real-time reverse transcription-PCR in vivo: detection of abortive viral replication. Curr Protoc Cell Biol. 2010;Chapter 26:Unit26.26.

20. Kärber G. Beitrag zur kollektiven Behandlung pharmakologischer Reihenversuche. Naunyn Schmiedebergs Arch Exp Pathol Pharmakol. 1931;162:480-3.

21. Spearman C. The method of 'Right and Wrong Cases' ('Constant Stimuli') without gauss's formulae. Br J Psychol 1904-1920. 1908;2:227-42.

22. DeVincenzo JP, El Saleeby CM, Bush AJ. Respiratory syncytial virus load predicts disease severity in previously healthy infants. J Infect Dis. 2005;191:1861-8

23. DeVincenzo JP, Wilkinson T, Vaishnaw A, Cehelsky J, Meyers R, Nochur S, et al. Viral load drives disease in humans experimentally infected with respiratory syncytial virus. Am J Respir Crit Care Med. 2010;182:1305-14.

24. Cormier SA, You D, Honnegowda S. The use of a neonatal mouse model to study respiratory syncytial virus infections. Expert Rev Anti Infect Ther. 2010;8:1371-80.

25. Empey KM, Orend JG, Peebles Jr RS, Egana L, Norris KA, Oury TD, et al. Stimulation of immature lung macrophages with intranasal interferon gamma in a novel neonatal mouse model of respiratory syncytial virus infection. PLoS One. 2012:7:e40499.

26. Openshaw PJ, Tregoning JS. Immune responses and disease enhancement during respiratory syncytial virus infection. Clin Microbiol Rev. 2005;18:541-55.

27. Mobbs KJ, Smyth RL, O'Hea U, Ashby D, Ritson P, Hart CA. Cytokines in severe respiratory syncytial virus bronchiolitis. Pediatr Pulmonol. 2002;33:449-52.

28. Sung RY, Hui SH, Wong CK, Lam CW, Yin J. A comparison of cytokine responses in respiratory syncytial virus and influenza $A$ infections in infants. Eur J Pediatr. 2001;160:117-22.

29. Ripple MJ, You D, Honnegowda S, Giaimo JD, Sewell AB, Becnel DM, et al. Immunomodulation with IL-4R alpha antisense oligonucleotide prevents respiratory syncytial virus-mediated pulmonary disease. J Immunol. 2010;185:4804-11.

30. You D, Marr N, Saravia J, Shrestha B, Lee Gl, Turvey SE, et al. IL-4Ralpha on CD4+ T cells plays a pathogenic role in respiratory syncytial virus reinfection in mice infected initially as neonates. J Leukoc Biol. 2013;93:933-42.

31. Han J, Dakhama A, Jia Y, Wang M, Zeng W, Takeda K, et al. Responsiveness to respiratory syncytial virus in neonates is mediated through thymic stromal lymphopoietin and OX40 ligand. J Allergy Clin Immunol. 2012;130:1175-86

32. Hotard AL, Lee S, Currier MG, Crowe Jr JE, Sakamoto K, Newcomb DC, et al. Identification of residues in the human respiratory syncytial virus fusion protein that modulate fusion activity and pathogenesis. J Virol. 2014;89(1):512-22.

33. McNamara PS, Ritson P, Selby A, Hart CA, Smyth RL. Bronchoalveolar lavage cellularity in infants with severe respiratory syncytial virus bronchiolitis. Arch Dis Child. 2003:88:922-6.

34. Welliver TP, Garofalo RP, Hosakote Y, Hintz KH, Avendano L, Sanchez K, et al. Severe human lower respiratory tract illness caused by respiratory syncytial virus and influenza virus is characterized by the absence of pulmonary cytotoxic lymphocyte responses. J Infect Dis. 2007;195:1126-36.

\section{Submit your next manuscript to BioMed Central and take full advantage of:}

- Convenient online submission

- Thorough peer review

- No space constraints or color figure charges

- Immediate publication on acceptance

- Inclusion in PubMed, CAS, Scopus and Google Scholar

- Research which is freely available for redistribution 